\title{
UNAS NOTAS DE CRÍTICA TEXTUAL SOBRE NOMBRES HEBREOS EN PACIANO DE BARCELONA
}

The ms. Reginensis 331 maintains the Hebrew names of Pacian's text in their genuine form. This is witnessed by contemporary biblical mss. and by some Latin writers, particularly Tertullian and Cyprian.

En Paciano de Barcelona los nombres hebreos presentan una cierta variedad como, por ejemplo, daniel $\mid$ danihel $\mid$ danihelus, que los editores han reducido generalmente a la tercera declinación o han considerado indeclinables. Semejante variedad no es exclusiva de Paciano. Se encuentra también en Tertuliano y Cipriano entre otros. Con los nombres hebreos en los escritores cristianos latinos ocurre algo parecido a lo que sucedió con los nombres griegos en los escritos paganos latinos, que algunos declinaron por la forma griega y otros por la latina según lo atestigua el gramático Donato: Meminerimus autem Graeca nomina ad Graecam formam melius declinari, etsi illa nonnulli ad Latinos casus conantur inflectere ${ }^{\prime}$. Los nombres hebreos se hallan, pues, en un mismo escritor como indeclinables, es decir, según su forma hebrea, o declinados por la flexión griega o pasados a los casos latinos. Ocupan nuestra atención en estas páginas: Beliab $\mid$ Beliae, Belzebul, Daniel $\mid$ Danihel $\mid$ Danihelum, Ezechielum, Iohannis | Iohannes | Iohannen | Iohannē, Isac, Lucanum, Moseum | Moyseum | Moyses, Neniuitas, Solomonis.

\section{Beliab | Beliae}

nec ... conuentio christi ad Beliab (Tract. XIX 1)2

beliab $R$ belial GP Belial edd. omn.

nos idolo et beliae iungimur (Tract. XIX 3)

Ars Minor II 10: $K G L$ IV p. 370, 15-17.

2 Las referencias remiten a la edición de L. Rubio Fernández, San Paciano. Obras. Universidad de Barcelona 1958. El opúsculo De Paenitentibus se cita por mi edición, Valencia 1982. La abreviatura Tract. corrige Ep III que carece de fundamento en la tradición mss, la cual reza Contra tractatus nouatianorum. Véase mi co- 
En hebreo Belial, como es sabido, designaba el poder enemigo de

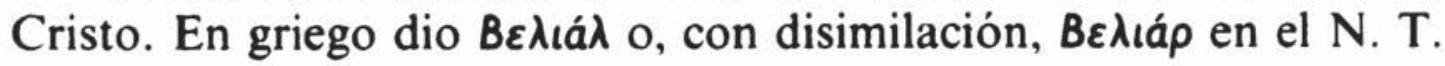

Tertuliano cita el versículo correspondiente de la Carta de San Pablo a los Corintios: Quae consonantia Christo et Belial; Quae communio Christo et Beliae ${ }^{3}$ y en otra ocasión alude al mismo versículo con estos términos: Quod est commercium damnaturis cum damnandis? Opinor quod Christo et Beliae ${ }^{4}$. También Prudencio ofrece la declinación por el tema en -a-: praeceptor Belia y principe Belia ${ }^{5}$. San Jerónimo escribe: Beliar, caeca angustia siue caecum lumen, uel filius praeuaricationis; sed

municación: Género literario de la Carta segunda de Paciano de Barcelona: Clasificación en Actas del VII Congreso Español de Estudios Clásicos. Madrid 20-24 abril 1987. Madrid 1989, II, pp. 457-461.

Interpretación de las abreviaturas usadas en el aparato crítico:

$R=$ Codex Reginensis Lat. 331 med. saec. IX.

$R^{\prime}=$ Codex Reginensis Lat. 331 a Floro Lugdunensi med. saec. IX emendatus.

$L=$ Codex Lugdunensis 5804 saec. XII.

$V=$ Codex Vitry-le-François 2 saec XII a. 1944 deperditus, at photographice seruatus. ( $L$ et $V$ excerpta continent, et eadem).

$G=$ Codex Gratianopolitanus $262 \mathrm{saec}$. XII.

$P=$ Codex Parisinus Lat. 2182 saec. XII-XIII.

\section{Ediciones}

$A g=$ Editio Ios. Sáenz de Aguirre in Collectione Maxima Conciliorum Hispaniae a. 1753. 1982.

Ang = Editio Libri De Paenitentibus Angelo Anglada curante, Valentiae a.

Barth = Editio K. Barthii Paraenetici ad Poenitentiam a. 1655.

Bigne $^{1 . . .}=$ Editio M. de La Bigne in Sacra Bibliotheca Sanctorum Patrum a. $1575,1589,1610,1618,1624,1644,1654,1677$.

Bigne $=$ praecedentium editionum consensus.

Brf = Emendatio a Clarissimo J. G. Ph. Borleffs in Zwei neue Schriften Pacians?: $M n 1939$ inuenta.

$F l o=$ Editio H. Florezii in España Sagrada a. 1859.

Gal = Editio P. Galesinii apud Aldum Manutium Aldi Filium a. 1564.

Gnd = Editio Gallandii in Bibliotheca Veterum Patrum a. 1770.

Migne = Editio in Patrologia Latina XIII a. 1845.

Nog = Editio V. Noguera Ramón a. 1780.

Pey $=$ Editio Ph. H. Peyrot a. 1896.

$R u b=$ Editio L. Rubio Fernández a. 1958.

$T i l=$ Editio princeps Ioh. Tillio curante a. 1538 .

Los puntos que se leen en los pasajes aducidos de Paciano reproducen las distinctiones de $R$, ms que conserva la puntuación original del propio Paciano.

${ }^{3}$ Pud. XV 5 (CCh SL II p. 1311, 1); Coron. X 7 (ib. p. 1055, 43). Para estas citas se ha consultado G. Claesson, Index Tertullianeus, Parisiis 1974. Pasaje bíblico II Cor. 6, 15.

${ }^{4}$ Cult. fem. I 2, 5 (CCh SL I p. 346, 40).

5 Hamart. 520 (CCh SL CXXVI p. 134); Psych. 714 (ib p. 175). Cf. R. J. Deferrari-J. M. Campbell, Concordance of Prudentius. Hildesheim 1966. 
rectius Belial dicitur ${ }^{6}$. Los nombres hebreos declinados por el tema en - $a$ - no son ninguna rareza en la literatura cristiana latina. Leemos, por ejemplo: Cepha -ae, Esthera -ae, Iuditha -ae ${ }^{7}$. La Vulgata declina Maria $-a e^{8}$. En el propio Paciano leemos Adam indeclinable y gen. Adae ${ }^{9}$. La forma Belia corresponde a la flexión griega que se encuentra en los $\mathrm{Pa}$ -

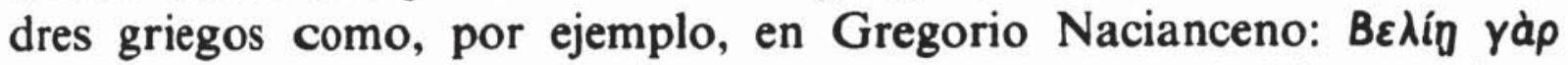

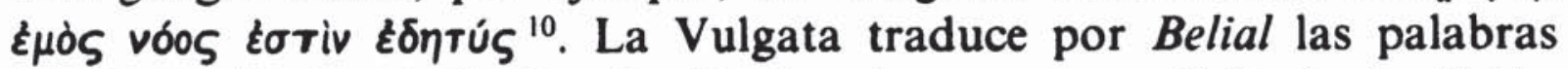

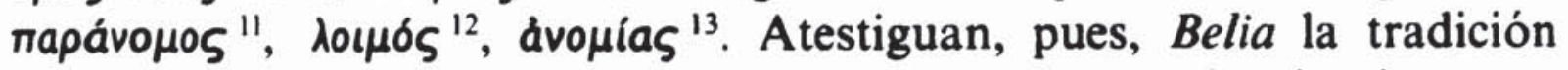
patrística griega, Tertuliano - fuente de Paciano - y Prudencio, entre otros. Estos hechos excluyen toda objeción posible a la forma beliae en Paciano. Dado el esmero y atención del escriba del Reginensis ${ }^{14}$, no cabe duda alguna de que la otra forma, beliab, figuraba igualmente en el modelo de $R$. Habida cuenta de la cercanía de este arquetipo con el original, resulta también genuina la lectura beliab. El copista del Gratianopolitanus 262 prefirió la forma de la Vulgata belial, que a su vez transcribió el amanuense del Parisinus 2182. La editio princeps, como en otras ocasiones, modificó el texto en ambos pasajes y escogió Belial, que adoptaron las ediciones posteriores. La editio princeps carece de autoridad, porque se ha conservado su modelo, que es el Reginensis Lat. $331^{15}$.

Belzebul

Hic non expellit daemonia nisi in belzebul principem daemoniorum (Tract. XV 5) ${ }^{16}$

${ }^{6}$ Liber interpretationis hebraicorum nominum 76,$5 ; 182,96 ; 188,69$ (PL XXIII col 97). Véase también: Fr. Wutz, Onomastica Sacra. Untersuchungen zum Liber Interpretationis Nominum Hebraicorum des hl. Hieronymus. 1. Hälfte. Quellen und System der Onomastica. Leipzig 1914 (TU XLI 1).

7 Clementis Romani Epistola ad Corinthios caps. 47, 55.

${ }^{*}$ Deut. 24, 9; Ioh. 11, 1; Mt. 1, 16; ib. 20; Mc. 6, 3; Lc. 1, 46; 2, 34; Act. 1, 14.

${ }^{\rightarrow}$ Bapt. I 3 bis; II 1; III 3; V 1; VI 1.

${ }^{10}$ Carm. 2, 1, 345 (PG XXXVII, col. 996 A).

"Deut. 13, 13; Iud. 19, 22; II Reg. 16, 7; 20, 1.

12 I Reg. 1, 16; 2, 12; 10, 27; 25, 17; II Par. 13, 7.

13 II Reg. 22, 5; Nah. 1, 15 (2,1).

14 Ángel Anglada, Las obras de Paciano publicadas por V. Noguera y Edición critica del Liber de Paenitentibus. Universidad de Valencia 1982, p. 24.

is Ángel Anglada, La Editio princeps de las obras de Paciano de Barcelona en Miscel-lània Sanchis Guarner. Quaderns de Filologia. Universitat de València 1984. II, pp. 17-22.

${ }_{16}$ P. Brosa Rocabert, Nouatianaea. Estudio de las citas biblicas en las fuentes latinas del novacianismo. Tesis de Doctorado mecanografrada, dirigida por el autor de este artículo, pp. 305, 308, 313-315 transcribe por confusión Beelzebul en vez de helzebul. 
belzebul $R\left(s\right.$. l. he s. s. b $\left.R^{\prime}\right)$ behelzebub $R^{\prime} G P$ Beelzebub edd. omn. principem $R$ (exp. $\left.\mathrm{m} R^{\prime}\right)$ principe $R^{\prime} G P$ edd. omn.

Los códices de los Evangelios Bobiensis ( $k$ s. Iv-v), Bezae Cantabrigiensis ( $d$ s. v), Palatinus ( $e$ s. v), casi contemporáneos de Paciano, escriben belzebul ${ }^{17}$. Entre los escritores cristianos latinos se lee belzebul en Cipriano: Si patremfamilias dixerunt Belzebul ${ }^{18}$. Tertuliano declina ac.: principem daemoniorum, quem Belzebulem ... dixerat ${ }^{19}$; abl.: in Belzebule dictus est eicere daemonia: "Si ego inquit in Belzebule eicio daemonia...» ${ }^{20}$, "Si ego in Belzebule, filii uestri in quo? Quasi suggillaret in Belzebule eicientes ... nec illi in Belzebule eiciebant ${ }^{21}$, hic non expellit daemonia nisi in Belzebule ${ }^{22}$. Prudencio escribe: Belzebulis callida | commen$t^{23}$. Debía ser muy corriente belzebul, porque Jerónimo por una razón etimológica recomienda belzebub: 'Beelzebub' ... in fine ergo nominis ' $B$ ' littera legenda est non ' $L$ ', 'musca' enim 'zebub' uocatur ${ }^{24}$. Con principem concuerda $k$ : belzebul principem daemoniorum ${ }^{25}$, lo que confirma la autenticidad del ac. principem. Es también seguro belzebul.

El pasaje que nos ocupa presenta importantes paralelismos con otro de Ambrosio en el tratado De Paenitentia.

\section{Pacianus}

Post haec proponis. et dicis scriptum esse per dominum. "Omne peccatum et blasphemia remittetur hominibus. Qui autem in spiritum sanctum peccauerit. non dimittetur ei neque hic neque in futurum". Aut ego fallor. aut istud exemplum contra te ualet. Nam si omne peccatum et blasphemia relaxabitur. uides ueniam paenitentibus non negari. Ergo omne peccatum. ergo ipsa quoque blasphemia. ... Sed "qui in spiritu sancto blasphemauerit ait. non remittetur ei".

17 A. Jülicher, Itala. Das Neue Testament in altlateinischer Uberlieferung nach den Handschriften herausgegeben von -. Matthaeus' Evangelium y Verzeichnis der Handschriften p. VII.

${ }_{18}$ Quir. III 75 (CCh SL III p. 161, 7. R. Weber, editor del CCh, escribe en el texto Belzebul y anota en el aparato critico que en los mss $P N X$, testigos del texto más puro (cf. Introduction aux ouvrages 'Ad Quirinum' et 'Ad Fortunatum' $p$. LVIII) se lee belzebub frente a $L F$, testigos también del texto más puro, que dan belzebul junto con $R W Q M b$ que copian beelzebul. Dado que $L^{2} F^{2}$ corrigen belzebub, no es de extrañar la enmienda de Floro de Lyon en Paciano.

Para las citas se ha consultado P. Bouet-Ph. Fleury-A. Goulon-M. Zumghedau, Cyprien. Traités. Concordance, Hildesheim-Zurich-Nueva York 1986.

${ }_{19}$ Marc. IV, XXVI 12 (CCh SL I p. 617, 9 s).

${ }^{20} \mathrm{Ib} .10$ (ib. $\left.16 \mathrm{~s}\right)$.

2) Ib. 10-11 (ib. 20-23).

22 Ib. XXVIII 2 (ib. p. 621, 21).

${ }^{23}$ Per. 5, 267 (CCh SL CXXVI p. 303).

24 Liber interpretationis nominum hebraicorum 97 (PL XXIII col 845 s B).

${ }^{25} \mathrm{Cf}$. P. W. Hoogterp, Étude sur le latin du Codex Bobiensis (k) des Évangiles, Wageningen 1930, p. 19. 
Soles totas percurrere lectiones. Cur hic non legisti. quid sit 'istud in spiritu'. Habes supra scriptum. quod cum dominus daemonia uerbo fugaret. et uirtutes multas spiritali uigore compleret. dixisse pharisaeos. "Hic non expellit daemonia. nisi in belzebul principem daemoniorum". ... Hoc est ergo quod non dimittetur. Reliqua bonis paenitentibus frater simproniane donantur ${ }^{26}$.

\section{Ambrosius}

Perlatum est tamen ad nos etiam illud uos obicere solere quod dicatis scriptum esse: "Omne peccatum et blasphemia remittetur hominibus, spiritus autem blasphemiae non remittetur hominibus ...". Quo exemplo omnis adsertio uestra destruitur et resoluitur. Scriptum est enim: "Omne peccatum et blasphemia remittetur hominibus». Cur igitur non remittitis? Cur ligatis uincula quae non soluitis? Cur nodos nectitis quos non relaxatis? Remittite caeteris, agite de his quos peccantes in Spiritum Sanctum euangelica auctoritate in perpetuum adstringi putatis. Et tamen quos adstringat consideremus, repetentes superiora lectionis ipsius, ut euidentius comprehendamus. Dicebant ludaei: "Hic non eicit daemonia nisi in Belzebul principe daemoniorum". Respondit Iesus: "Omne regnum diuisum contra se destruetur ... Quod si ego in Belzebul eicio daemonia, filii uestri in quo eiciunt?». De his utique expressum uidemus qui Dominum Iesum in Belzebul eicere daemonia loquebantur ... Et ut cognosceremus quia de hac dixit blasphemia, adiunxit: "Progenies uiperarum. quomodo potestis bona loqui, cum sitis mali?". Hos ergo qui haec loquuntur, negat ad ueniam pertinere... Et tamen non interclusit ei spem ueniae, quem inuitauit ad paenitentiam 27 .

\section{La comparación de ambos pasajes yuxtapuestos permite advertir los} paralelismos siguientes:

\section{Pacianus}

Post haec proponis et dicis

scriptum esse per dominum

"Omne peccatum et blasphemia remittetur hominibus

qui autem in spiritum sanctum peccauerit non dimittetur ei

neque hic neque in futurum».

Aut ego fallor

aut istud exemplum contra te ualet.

Nam

si «omne peccatum et blasphemia relaxabitur"

\section{Ambrosius}

Perlatum est tamen ad nos etiam illud uos obicere solere quod dicatis scriptum esee "Omne peccatum et blasphemia remittetur hominibus

Et quicumque dixerit uerbum contra Filium hominis non remittetur ei;

qui autem dixerit contra Spiritum Sanctum non remittetur ei neque in hoc saeculo neque in futuro". Quo exemplo omnis adsertio uestra destruitur et resoluitur. Scriptum est enim: "Omne peccatum et blasphemia remittetur hominibus".

Cur igitur non remittitis? Cur ligatis

\footnotetext{
26 Tract. XV 3, 5-6.

27 Paen. IV 20-23 (SCh 179).
} 
uides ueniam paenitentibus non negari. Ergo omne peccatum. Ergo ipsa quoque blasphemia.

Sed "qui in spiritu sancto blasphemauerit ait non remittetur ei».

Soles totas percurrere lectiones. Cur hic non legisti quid sit istud 'in spiritu"?

Habes supra scriptum. quod cum dominus daemonia uerbo fugaret et uirtutes multas spiritali uigore compleret dixisse pharisaeos:

"Hic non expellit daemonia nisi in belzebul principem daemoniorum".

... Hoc est ergo quod non dimittetur.

Reliqua bonis paenitentibus frater simproniane donantur. uincula quae non soluitis? Cur nodos nectitis quos non relaxatis?

... Et tamen quos adstringat consideremus.

repetentes superiora lectionis ipsius ut euidentius comprehendamus

Dicebant Iudaei:

«Hic non eicit daemonia nisi in Belzebul principe daemoniorum".

... Hos ergo qui haec loquuntur, negat ad ueniam pertinere.

... Et tamen non interclusit ei spem ueniae, quem inuitauit ad paenitentiam.

En lugar distinto en cada uno de ambos pasajes corren también paralelos en el contenido y en alguna palabra estos párrafos:

\section{Pacianus}

In caeteris quippe peccatis.

aut errore labimur.

aut metu frangimur.

aut carnis infirmitate superamur.

Haec caecitas est.

Non uidere quod uideas.

El sancti spiritus opera.

diabolo deputare.
Ambrosius

Remittite ceteris,

agite de his

quos peccantes in Spiritum Sanctum

euangelica auctoritate in perpetuum adstringi putatis.

Respecto del contenido, Remittite de Ambrosio atestigua que los demás pecados merecen ser perdonados, mientras Paciano expresa el motivo que justifica esta indulgencia, pues se cometen por fragilidad humana. Con un tecnicismo juridico agite de invita Ambrosio a los novacianos a que procedan contra quienes ofenden al Espíritu Santo. Paciano es tajante en la sentencia: "Es ésta la ceguera» Haec caecitas est. Es el pecado imperdonable del ciego que no quiere ver. Mientras Paciano precisa en qué consiste el pecado contra el Espíritu Santo sancti spiritus opera. diabolo deputare, Ambrosio se limita a unos términos generales peccantes in Spiritum Sanctum. Confirma este paralelismo de contenido el léxico, por cuanto se repiten caeteris y deputare - putatis. Este segundo en modo y forma distinta y relacionado con palabras también distintas. 
Merece especial atención que Mt 12, 24 no aparezca en ningún otro escritor antinovacianista contemporáneo, ni en Cipriano, ni en $\mathrm{De} P a e$ nitentia y De Pudicitia de Tertuliano, sino sólo en el Aduersus Marcio$n^{n}{ }^{28}$. No es de suponer que Paciano hubiese leído el De Paenitentia de Ambrosio, escrito en los años 387-390, ni Ambrosio a Paciano, cuya tradición manuscrita no había salido de la Tarraconense en el s. IV ${ }^{29}$.

Paciano responde a un novacianista muy concreto, Simproniano, que le había mandado todo un tratado y estaba muy seguro de sus ideas, pues no había encontrado a nadie que le convenciera en sentido contrario, según una afirmación de él mismo citada por Paciano: nullus inuentus sit qui te reuinceret. aut persuadere tibi posset. contra quam crederes $^{30}$. La obra de Ambrosio, en cambio, tiene un carácter pastoral. Estas dos circunstancias explican ciertas diferencias de léxico tales como el uso del singular en Paciano y el uso del plural en Ambrosio por cuanto el diálogo es adaptado respectivamente a un solo corresponsal o a los novacianistas en general. Véase con más detalle:

\section{Pacianus}

proponis et dicis

istud exemplum contra te ualet

uides ueniam paenitentibus non negari

Soles totas percurrere lectiones

Cur hic non legisti ...? Habes supra scriptum.
Ambrosius

dicatis

Quo exemplo omnis adsertio uestra destruitur et resoluitur.

Cur igitur non remittitis? Cur ligatis uincula quae non soluitis?

Cur nodos nectitis quos non relaxatis? repetentes superiora lectionis ipsius ut euidentius comprehendamus (superiora lectionis anterior).

En la introducción Paciano escribe dicis y Ambrosio dicatis, por razón de los destinatarios respectivos. En ambos el verbo dicere introduce scriptum esse. El texto biblico presenta sólo la variante expellit en $\mathrm{Pa}$ ciano, eicit en Ambrosio. El pecado que no se perdona es introducido en ambos por qui autem. Ambos califican de prueba el texto bíblico mediante la palabra exemplum, aunque es éste su significado. En Paciano leemos: Soles totas percurrere lectiones y en Ambrosio: repetentes superiora lectionis ipsius. También en Ambrosio se halla el verbo solere al comienzo del pasaje: uos obicere solere. El adjetivo superiora ambrosiano se corresponde con el adverbio supra de Paciano: Habes supra scrip-

28 Véase nota 22.

29 Ángel Anglada, La tradición manuscrita de Paciano de Barcelona en EMERITA 35, 1967, pp. 137-161, especialmente 140 s. y 154-161.

${ }^{30}$ Ep. I, II 3. 
tum. En ambos el argumento se cierra con el pasaje del evangelio de San Mateo, introducido con el verbo dicere. En Paciano: dixisse pharisaeos y en Ambrosio: Dicebant Iudaei. La insistencia Aut ego fallor no se lee en Ambrosio. La frase omnis adsertio uestra destruitur et resoluitur es más general que la de Paciano contra te ualet. La prueba de la refutación va introducida en ambos por una ilativa, aunque distinta: En Paciano Nam, en Ambrosio enim, siendo el medio de la argumentación el mismo texto bíblico, que Ambrosio introduce añadiendo Scriptum est. La conclusión igitur del obispo de Milán corre paralela con el ergo de Paciano preparado y reiterado mediante la condicional si. La ambientación de la blasfemia es extremadamente breve en Ambrosio, si bien el texto bíblico va introducido en ambos casi con los mismos términos: dixisse pharisaeos y Dicebant Iudaei. Mientras Paciano dice expellit en la cita escriturística, Ambrosio escribe eicit. No sé si quizás el primero pensó evitar el sentido debilitado de eicio en latín tardío de 'conducir fuera' ${ }^{31}$, y prefirió expellit. De todos modos, expellere sólo aparece aquí en toda la obra de Paciano y eicere no aparece nunca. Sabatier ${ }^{32}$ menciona únicamente a Hilario, Ambrosio y Agustín para eicit, mientras que para expellit y expelleret cita a Paciano y Agustín, respectivamente. El Codex Bobiensis $(K)$ reza expellit, lo que tiene especial interés por la cercanía de su texto con el de Cipriano: Si et satanas satanan expellit in se diuisus est ${ }^{33}$.

El ms Reginensis de Paciano copia: Sed qui in spiritu sancto blasphemauerit ait non remittetur ei. A partir de V. Noguera ${ }^{34}$ las ediciones corrigen ait en ais. No es insólito en Paciano Sed para introducir la objeción y ponerla en boca del adversario. Así se lee: Sed paenitere non licuit, o bien con el verbo inquam: Sed et uos inquies episcopi talia cur probatis $^{35}$. Interpretado en este sentido, el sujeto de ait no es Simproniano, por cuanto quien alega el versículo es Simproniano, pero quien

${ }^{31}$ E. Löfstedt, Philologischer Kommentar zur Peregrinatio Aetheriae. Untersuchungen zur Geschichte der Lateinischen Sprache. Upsala/Darmstadt 1962, p. 264.

32 Bibliorum Sacrorum Latinae Versiones Antiquae seu Versio Italica. Reims 1743 1749/Turnhout 1976, II, p. 71.

${ }^{33}$ C. Cipolla, Osservazioni paleografiche sul Codice Evangelico $k$. en Il codice Evangelico $k$ della Biblioteca Universitaria di Torino, Turín 1913: Cap. X, L'età e la patria del codice $k$, p. 54.

${ }_{34}$ D. Paciani Episcopi Barcilonensis Opera quae extant, Valencia 1780, p. 158 XXXI. Sobre esta edición véase: Ángel Anglada, Las Obras de Paciano publicadas por V. Noguera y Edición critica del Liber De Paenitentibus, Valencia 1982.

${ }^{35}$ Ep. I, VI 1. Para esta carta puede verse la edición del autor de estas líneas: El texto de Paciano en la Bibliotheca Patrum de Marguerin de La Bigne en Homenaje a Pedro Sáinz Rodriguez, Fundación Universitaria Española, Madrid 1986, I, pp. 309-337. Tract. VII 1. 
lo dice es Dios. La frase es del Evangelio y pronunciada por Jesucristo. Por tanto, la lectura genuina es la de la tradición manuscrita, es decir, ait.

Paciano presenta un ritmo más cuidado que el de Ambrosio, circunstancia que explica algunas diferencias. En distinctio plena se leen en Paciano las cláusulas ${ }^{36}$ : omne peccatum $1_{\gamma}$ (lin. 7), quoque blasphemia $2_{\gamma}$ (lín. 7), percurrere lectiones e $3_{\delta}$ (lín. 9), istud 'in spiritu' $2_{y(\delta)}$ (lín. 10), simproniane donantur $1_{\gamma}$ (lín. $15 \mathrm{~s}$ ). En distinctio media: uigore compleret $1_{y}$ (lín. 12). En introducción del texto bíblico: esse per dominum $1_{\gamma(\delta)}^{3}$, dixisse pharisaeos $1_{\gamma}^{2}$ (lín. 12); En interior de miembro: istud exemplum $1_{\gamma}$ (lín. $4 \mathrm{~s}$ ), omne peccatum $1_{y}$ (lín. 5). No faltan dos cláusulas entrelazadas: uéniam paeniténtibus $\mathrm{e}_{\delta}$ non negari e $3 \delta_{(\varepsilon)}$ (lín. 6). En Ambrosio encontramos destruitur et resoluitur e $4_{\delta(\varepsilon)}$. Si ipsius se escande como antibaquio: lectionis ipsius $1_{y}$ (lín. $11 \mathrm{~s}$ ); uéniam pertinere $\mathrm{e} 3_{\delta}$. No obstante ser más largo, el texto de Ambrosio ofrece tres cláusulas, mientras que el de Paciano presenta doce. Esta particularidad del numerus es una prueba segura de que Paciano modifica la fuente adaptándola a su ritmo y estilo, en cambio, Ambrosio guarda una mayor fidelidad.

Estas correspondencias demuestran que ambos escritores remontan en este pasaje a una fuente común, hoy perdida ${ }^{37}$. Si los paralelismos estudiados derivan de un mismo origen, la concordancia en el nombre de bezebul no puede tener una procedencia distinta. Por tanto, si Paciano, además de coincidir con Ambrosio, concuerda con Cipriano y, en parte, con Tertuliano, cuyos escritos copia, a veces literalmente, la forma belzebul resulta ser más antigua que belzebub y, en consecuencia, debe restituirse la lectura del Reginensis belzebul, que es la genuina.

\section{Daniel | Danihel | Danielus}

Danielus cum sodalibus suis. sacco tectus et cinere. ieiunio etiam exanguis haec loquitur. (Paen X 4, 267 s)

Danielus $R$ Til Gal Bigne Barth Gnd Migne Ang danihelus fol $113^{\text {th }} L$ danihel fol $42^{\text {rh } V}$ daniel GP Cypr. Laps. 31 Bigne ${ }^{8}$ cett. edd.

Este texto forma parte de un pasaje que resume otro de Cipriano. Comparemos ambos fragmentos:

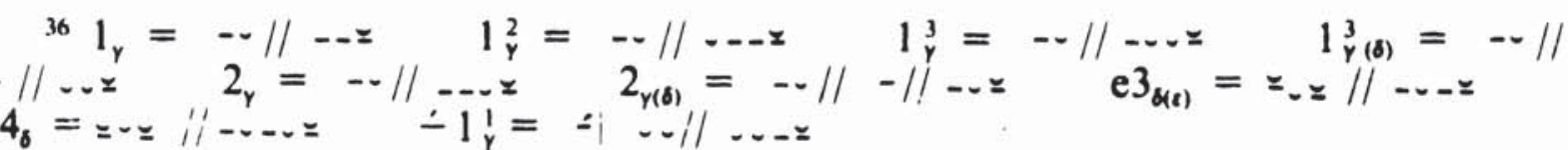

${ }^{37}$ P. Brosa, Op. cit., pp. 305-315. 


\section{Pacianus}

Danielus cum sodalibus suis. sacco tectus et cinere. ieiunio etiam exanguis. haec loquitur. Peccauimus. facinus admisimus. impie gessimus. transgressi sumus praecepta et iudicia tua. De azaria itidem. scriptura diuina. Stans inquit azarias precatus est. et aperuit os suum et exomologesin faciebat deo. simul cum sodalibus suis.

Danielus $R$ Til Gal Bigne Barth Gnd Migne Ang danihelus fol $113^{\text {vb }} \mathrm{L}$ danihel fol $42^{r b} V$ daniel GP Cypr. Laps. 31 Bigne ${ }^{8}$ cett. edd. textus $V$ etiam om. $V$ Et Azaria Barth itidem ex idem eras. partim prior. d s.s. ti $P$ precatis $R$ (exp. i s.l. u $R^{\prime}$ ) precatus $R^{\prime}$ codd. edd. omn. aperuit $R$ Cypr. l.c. Ang (oblitt. uit s.l. iens $R^{\prime}$ ) aperiens $R L V G P$ cett. edd. et exomologesin $R$ Cypr. l.c. Ang (oblitt. et $R^{\prime}$ ) exomologesin GP (uel -m) edd.

\section{Cyprianus}

Loquitur scriptura diuina: «Stans inquit Azarias precatus est et aperuit os suum, et exomologesin faciebat deo simul cum sodalibus suis in medio ignis". Daniel quoque post fidei adque innocentiae suae multiplicem gratiam, post dignitatem domini circa uirtutes ac laudes suas saepe repetitam, ieiuniis adhuc promereri deum nititur; in sacco et cinere uolutatur exomologesin faciens dolenter et dicens ${ }^{38}$.

No obstante la diversidad en el orden, se advierten fácilmente los paralelismos siguientes:

\section{Pacianus}

Danielus cum sodalibus suis sacco tectus et cinere. ieiunio etiam exanguis. haec loquitur

De azaria itidem scriptura diuina. Stans inquit azarias precatus est. et aperuit os suum. et exomologesin faciebat deo. simul cum sodalibus suis.

\section{Ciprianus}

Loquitur scriptura diuina: Stans inquit azarias precatus est et aperuit os suum et exomologesin faciebat deo simul cum sodalibus suis in medio ignis. Daniel ... ieiuniis adhuc promereri deum nititur; in sacco et cinere uolutatur exomologesin faciens et dicens.

Se corresponden sacco tectus et cinere de Paciano y in sacco et cine$r e$ de Cipriano mediando, aparte de la preposición in, una diferencia, y es que el primero compone con una cláusula muy sonora como es tectus et cinere $1_{r(8)}^{3}$ frente a la de Cipriano cinere uolutatur $\left(-1_{y}^{1}\right)$ nada frecuente. No es de extrañar la discrepancia entre ieiunio etiam exanguis de Paciano y ieiuniis adhuc promereri deum nititur de Cipriano, porque hay en el primero una concisión debida a que resume. También loquitur corre paralelo, aunque en distinto lugar. Un relieve especial adquiere la cita bíblica al ser igual en ambos: Stans azarias precatus est. et aperuit

\footnotetext{
${ }^{38}$ Laps. 31 (CCh $S L$ III A pp. 238 s, 615-622).
} 
os suum e.q.s. Floro de Lyón escribió en el texto de Paciano iens encima de uit y tachó el et de delante de exomologesin para leer aperiens os suum, enmienda que pasó a toda la tradición manuscrita y a las ediciones, excepto la mía.

Una divergencia llama mayormente la atención. En De Lapsis Cipriano dice Daniel, en la edición del $C C h$, mientras que en el De Paenitentibus de Paciano se lee Danielus. Algo parecido ocurre con danihelum de Paciano, inspirado en De Lapsis en que reza Daniele abl. Conforme a estos hechos, es lógico pensar en una preferencia de Paciano por escribir danielus danihelum, es decir, por el tema en -o-.

Nisi danihelo inputabitur. quod a dario uindicatus est (Ep II, V 3)

danihelo $R$ fol $113^{\text {rh }}$ L Til Bigne ${ }^{12}$ Danielo Gal Bigne ${ }^{34}$ daniheli in ras. i fol $42^{\text {rh }}$ $V$ Danieli cett. edd.

Ipse tu illud ponis exemplum. Et si fuerint tres hi in medio eorum. noe. iob. et daniel. non liberabunt filios neque filias. e.q.s. (Tract. III 7) ${ }^{39}$.

eorum om. edd. praeter Nog Pey Rub.

Cyprianum beatissimum mihi pro contrario teste proponis. quia in epistula quae de lapsis. moysen et danihelum et iob orasse pro peccatoribus dicat nec impetrasse. dicente domino. etsi tres in medio eorum fuerint. noe iob et danihel. non liberabunt e.q.s. (Tract. XXII 3)

lapsis $R G P$ lapsis est edd. omn. danihelum $R$ danihelem GP Danielem edd. omn. moysen $R$ Til Bigne' edd. moysē $G$ moysem $P$ Bigne Mosem $G a l$ Noe (calc. (ind Migne) Pey Ruh.

Sed noe inquis et danihel et iob. (Tract XXIV 1)

Sed om. fol $117^{\mathrm{ra}} L$ fol $45^{\mathrm{ra}} \mathrm{V}$ oe $V$ danihel $R L P$ daniel $V G$ Daniel $e d d$. omn.

Estos pasajes ofrecen una heteroclisis. Así tenemos nom. danihelus, daniel, danihel; ac. danihelum; dat. danihelo.

En la antiquísima versión latina del Pentateuco (s. III-IV) ${ }^{40}$, conservada en un ms del s. vil custodiado en la Bibliothèque de la Ville de Lyon, el nombre del Sumo Sacerdote Eleazar reza eleazarum (ac.), eleazari (gen.), eleazaro (dat.). En la Vulgata el hermano de María y Marta se llama lazarus (nom.), lazare (voc.), lazarum (ac.) ${ }^{41}$.

${ }^{39} \mathrm{Ez} 14,16$ y 20.

40 Ulysse Robert, Pentateuchi Versio Latina Antiquissima e codice Lugdunensi. Parisiis 1881, v. Introduction pp. LI-LXI e Index Onomastique II 157-163.

${ }_{41}$ Lazarus Lc 16, 20; Ioh 11, 1; 2; 11; 14; 12, 1; 2; Lazare Ioh 11, 43; Lazarum Lc 16,$23 ; 24$; Ioh 11,$5 ; 12,9 ; 10,17$. 
En la versión latina (s. II) de la Carta de Clemente de Roma a los Corintios los nombres bíblicos presentan los temas en - $a-$, - $o-$, la tercera declinación o son indeclinables, como por ejemplo: Adae, Rahaba; Cainus, Isacus, Dauide, Ezechielem; Dauid, Iacob entre otros ${ }^{42}$. La versión latina de Ireneo traduce Danihelum, Danihelo, Danielo ${ }^{43}$, Eleazarum, Eleazaro, (nom.) Eleazar ${ }^{44}$.

Cipriano en sus tratados declina el nombre de Daniel por el tema en -o- danihelum ${ }^{45}$, por la tercera daniheli, danihele ${ }^{46}$ y como indeclinable danihel, daniel $^{47}$. En Tertuliano hallamos danielum, danihelo (dat. abl.), daniel (nom.), danielem (ac.), danielis (gen.), danieli, daniheli (dat.), daniele (abl. $)^{48}$. Una sola vez aparece en Prudencio: danielus ${ }^{49}$. En Lucifer de Cagliari encontramos danihel (nom. ac.), danielem (ac.) danielis (gen.), danihelo (dat.) ${ }^{50}$.

Amiano Marcelino nombra dos veces a un tal Daniel y ambas lo declina por el tema en -o-: danielum mittit ... Danielus post haec ... ${ }^{51}$.

Semejante heteroclisis remonta a la literatura griega cristiana en que los nombres hebreos ofrecen a veces dos formas, una literaria adaptada

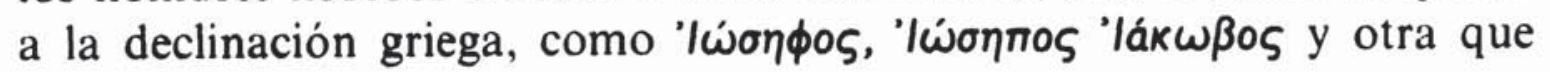

42 Caps. 29; 12; 4 seis veces Cainus $-m ; 31 ; 18 ; 17 ; 4 ; 19$. Véase n. 7.

4. Sven Lundström, Die Uberlieferung der lateinischen Irenaeus Ubersetzung (Acta Universitatis Upsaliensis, Studia Latina Upsaliensia, 18), Upsala 1985. p. 81. Fr. Blass-A. Debrunner, Neutestamentliche Grammatik, Göttingen 1943 p. 26 cita 'lákw-

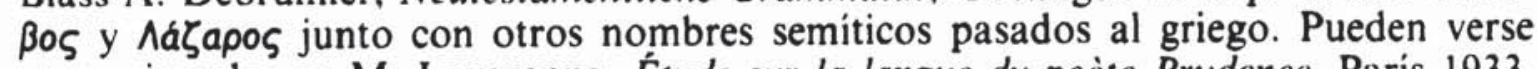
otros ejemplos en M. Lavarenne, Étude sur la langue du poète Prudence. París 1933. pp. 14-20. Véase también Hoogterp Op. cit., pp. 18-24.

4 Sven Lundström, Op. cit., p. 81.

45 Quir I 4 (CCh SL III p. 9, 10; II 17 (Ib. p. 53, 3) 26 (Ib. p. 63, 3); III 10 (Ih. p. 98,13$) 20$ (Ib. p. $117,78,80,90)$.

t6 Dom. Or. 21 (CCh SL III A p. 103, 96); Laps. 19 (Ib. III p. 232, 388).

47 Laps. 31 (CCh $S L$ p. 238, 618); Op. eleem. 11 (Ib. III A p. 62, 220); Quir. III 20 (Ib. p. 117, 87).

${ }_{48}$ Daniel passim. Danielum Scorp. VIII 7 (CCh SL II p. 1083, 28). Danielem Idolol. XVIII 1 (Ib. p. 1118, 20). Danielis Ie VII 7 (Ib. p. 1264, 8); IX 4 (Ib. p. 1267. 2); Iud. XIII I (Ib. p. 1384, 4); Marc. IV 14 (Ib. p. 565, 14); 41 (Ib. p. 658, 11). Danihelo (dat.) Iud. VIII 9 (Ib. p. 1359, 58). Danieli Ie IX 2 (Ib. 1265, 22); Or. XXV 5 (Ib. I p. 272, 13). Daniheli Marc. IV 10 (Ib. p. 564, 24). Danihelo (abl.) Iud. VIII 2 (Ib. II p. 1356, 8). Daniele An XLVIII 3 (Ib. p. 854, 19).

49 Cath. IV 7 (CCh SL CXXVI p. 21).

50 Danihel (nom.) Athan. I, XLI (CCh SL VIII p. 71, 42); II, IX (Ib. p. 92, 14; p. 93, 21; 23; 27); De non parc. XV (Ib. p. 223, 14); XXX (Ib. 252, 6; 7; 39); XXXI 4 (Ib. 254, 4); XXXII (Ib. 255, 7). Danihel (ac.) Athan. II, X (Ib: p. 94, 6s); XI (Ib. p. 95, 14). Danihelem Athan. II, X (Ib. p. 94, 6); Danihelo (dat.) Athan. II, IX (Ih. p. 93, 30). Véase, además, W. Hartel, Lucifer von Cagliari und sein Latein en ALLG III (1886) p. 35.

s1 V. Gardthausen, Ammianus Marcellinus, Stuttgart, Teubner, 1967, XXX 1, 11 y 16. 


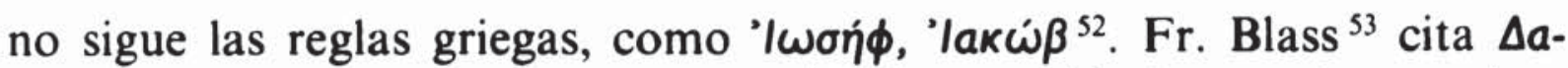
vıńरou del ms $D$ (s. v-vı). Esta duplicidad pasa al latín y en los comienzos de la literatura cristiana latina es mucho más frecuente, predominando en tiempos posteriores casi exclusivamente la forma indeclinable, aunque no falten los temas en $-a-$ y en $-o$ - así como la tercera declinación incluso en la misma Vulgata.

Todas estas consideraciones nos llevan a la conclusión cierta completamente de que las lecturas danielus, danihelum, danihelo no son una invención del escriba del Reginensis ni se deben a una corrupción, sino que son genuinas y como tales han de ser restituidas en el texto de $\mathrm{Pa}$ ciano.

\section{Ezechielum}

Nec apud ezechielum tacet dominus (Tract. III 6)

ezechielū $R$ iezechielē $G$ iezechielem $P$ Ezechielem $e d d$. omn.

Es éste el único lugar en que aparece el nombre del profeta en $\mathrm{Pa}$ ciano. La versión latina de la Carta de Clemente de Roma a los cristianos de Corinto declina ezechielem ${ }^{54}$. Tertuliano ofrece la flexión ezechiel (nom.), ezechielem (ac.), ezechielis (gen.), ezechieli (dat.) ${ }^{55}$. Cipriano, en cambio, prefiere el indeclinable en apud ezechiel ${ }^{56}$, mientras escribe una sola vez ezechielem ${ }^{57}$ y dos ezechielum ${ }^{58}$ en los tratados.

La literatura griega cristiana hace referencia a un poeta judio helenístico, escritor de tragedias de tema bíblico, que vivió en el s. II o quizás en el s. III a. C. Los pasajes que lo mencionan presentan el nomina-

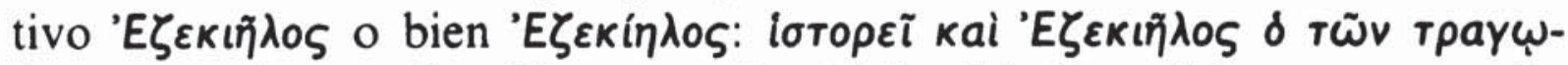

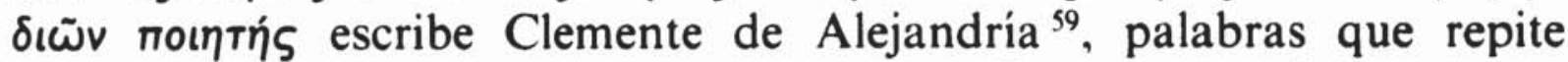
Eusebio de Cesarea ${ }^{60}$ adelantando el acento. Tampoco es ajena a seme-

s2 Fr. Blass, Op. c. pp. 26 y 27; A. Hilhorst, Sémitismes et latinismes dans le Pasteur d'Hermas, Nimega 1976, p. 167.

${ }^{53}$ Ib. p. 26; Mt 24, 15.

5417.

s5 Ezechiel Fug. XI 2 (CCh SL II p. 1149, 19); Prax. XIV 2 (Ib. p. 1176,2); Iud. XI 1 (Ib. p. 1380, 2). Ezechielem Carn. XXIII 6 (Ib. p. 915, 33); Ezechielis Marc. II, X 2 (Ib. I p. 486, 16); Marc. IV, XVII 1 (Ib. p. 585, 16); Pud. VII 18 (Ib. p. 1294, 77); Ezechieli Res. XXX 3 (Ib. II p. 959, 15).

so Ezechiel (nom.) Fort. IV (CCh SL III p. 190, 11); Fort. VIII (Ib. p. 198, 6).

57 Ezechielem Quir. I 21 (CCh SL III p. 15, 3).

s8 Ezechielum Quir. III 48, 8 (Ib. p. 137, 4); Quir. III 58 (Ib. p. 144, 15).

59 Stromm. I 23 (PG VIII col. $901 \mathrm{~A})$.

(n) Praep. Euang. IX 28 (PG XXI col. $736 \mathrm{C})$. 
jante declinación la Versión llamada de los LXX respecto de los nombres hebreos, pues en el Libro I de Esdra se lee, según la edición de A.

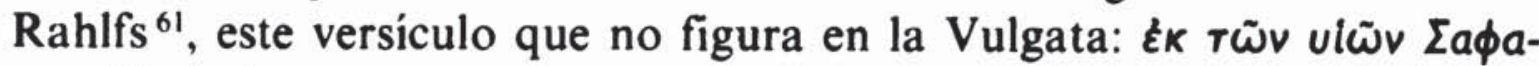
tiou Mixaniou.

A. Gruber fue el primero en llamar la atención sobre el tema en -ode los nombres hebreos en Paciano ${ }^{62}$, cuando reprocha a Peyrot que ezechielum bien merecía una nota, habida cuenta de que Claudiano Mamerto escribe Gabrielum (ac.), Gabrielo (dat. abl.), según la lectura de los mejores mss, conforme atestigua A. Engelbrecht en su estudio sobre el latín del presbítero galo ${ }^{63}$.

Todos estos hechos ponen de manifiesto la arbitrariedad del escriba de $G$ declinando el nombre del profeta por la tercera. $P$ copió fielmente la modificación de $G$. La misma corrupción sufren las ediciones, deudoras de la editio princeps cuyo modelo es $R$.

Debe restituirse, por tanto, y con toda certeza, ezechielum.

\section{Iohannes}

nunc audite iohannē. (paen IV 5, 100).

iohannẽ $R$ iohem GP Ioannem uel Joannem uel Johannem hic et ubique edd. omn.

Et adicis. quod Mattheus minus integre prosecutus sit complesse iohannen. (Tract XI 2).

distinctionem post adicis om. GP iohannen $R$ ioћem $G P$ ioannē Bigne ${ }^{267}$.

apud iohannen impleuerit. (Tract XI 2).

iohannen $R$ iohem $G P$

cur ergo illi capitulum iohannis adiungis. (Tract XI 5).

iohis $m g G$.

Post haec de sarmentis et uite proponis. Sic ait dominus apud iohannen. (Tract XVI 1).

proponis. Sic ait s.s. po ex pronisnis. Sic ait $R$ proponis. Sic ait $G P$ proponis sic, ait Bigne ${ }^{2 \cdot 7}$ edd. praeter Til Gal Bigne ${ }^{18}$.

${ }^{61}$ Septuaginta. Id est Vetus Testamentum graece iuxta LXX interpretes, Stuttgart 1935/1965, I, p. 805.

${ }_{62}$ Studien zu Pacianus von Barcelona, Munich 1901, p. 24.

${ }^{63}$ Untersuchungen über die Sprache des Claudianus Mamertus en Sitzungsberichte d. Wiener Akad. d. Wiss. 110, 1885, pp. 423-542, 7.73 (= 493). 
Sicut iohannis ait. (Tract XVI 2).

iohannis $R$ s. $l$. o ioћs ex ihs $G$ ioћs $P$ edd. omn.

Iohannes itidem. (Tract. XVI 3 Mt 3,1-12).

Estos siete pasajes ofrecen la siguiente declinación del nombre del evangelista o Bautista: nom. iohannes | iohannis, ac. iohannen | iohanne, gen. iohannis según $R$. Los mss $G$ y $P$, la editio princeps y con ella todas las ediciones prefieren la declinación de la Vulgata: -es, -em.

No es de extrañar que leamos en Paciano un ac. como iohannen. En latín, como es sabido, los nombres griegos hacen el ac. en -en o en -em. Así Socraten Socratem ${ }^{64}$, Diogenen más comúnmente Diogenem ${ }^{65}$, Simoniden Simonidem ${ }^{66}$ entre otros muchos ${ }^{67}$. Por lo que se refiere al nombre sagrado de Juan, el ac. iohannen de Paciano se halla en los mss más antiguos de los Evangelios, tales como $a$ (Vercellensis s. IV, contemporáneo de Paciano) en el que se lee iohannen Mc 5, 37; 14, 33, $b$ (Veronensis s. v) presenta uniformemente iohannen, según afirma E. S. Buchanan ${ }^{68}, f$ (Brixianus s. vi) Mc 3,17 , por ejemplo. También se encuentra la forma abreviada iohannē en $a$ Mt 4, 21; Lc 6, 14; Mc 10, 41, en $b \mathrm{Mt}$ 17,1 ; Lc 6, 14; en $f \mathrm{Mt} \mathrm{4,21.} \mathrm{No} \mathrm{falta} \mathrm{tampoco} \mathrm{la} \mathrm{forma} \mathrm{iohannem} \mathrm{en}$ $f$ Lc 9, $28^{69}$. Carece de interés aportar el testimonio de los escritores como Tertuliano y Cipriano entre otros, porque en las ediciones se ha unificado siempre iohannem.

Con los datos aducidos resulta incompatible cualquier razón con la que se pretenda justificar la enmienda del escriba de $G$ iohm si no es la de haber seguido la forma de la Vulgata. La misma explicación tiene la arbitrariedad de la editio princeps que modificó iohannen de $R$ y prefirió iohannem.

Respecto a la interpretación de iohannè, es dificil tomar una decisión, pues el signo de abreviatura tanto lo es de $m$ como de $n$. Tampoco

${ }^{64}$ Socratem Cic. Off. I 30, 108; III 3, 11; Tusc. I 42, 100; III 4, 8: V 4, 10; 4, 11. Socraten Tusc. V 34, 97, ed. M. Pohlenz en Teubner 1918/1965. Socraten se lee Off. I 30,108 en los mss. Vossianus Q 71 (V) que M. Pohlenz considera muy bueno y el Bernensis (c) del que M. Pohlenz escribe: «licet audacissime puram et genuinam quasi formam ac figuram Tullianam deformauerit, tamen pretiosissimus est et alterius familiae $X$, utpote mutilus est $L$, testis gravissimus, cui verum non semel soli debeatur». Cf. Praefatio, pp. VII y XIV.

${ }_{65}$ Diogenen Cic. Tusc. IV 3, 5. Diogenem Cic. Senect. 7, 23.

66 Simoniden Cic Nat. deor. I 22, 60. Simonidem Cic. Senect. 7, 23.

67 Themistoclen codd. Vc Cic. Off. I 30, 108. Themistoclem codd. edd.

${ }_{68}$ The four Gospels from the Codex Veronensis $(b)$. Oxford 1911 p. XIII. Véase también del mismo The four Gospels from the Codex Corbaiensis (ff or $f f^{2}$ ) Oxford 1907; A. Jülicher, Op. c. lugar correspondiente.

${ }_{69}$ A. Jülicher, $O p$. cit., lugar correspondiente. 
se puede argüir que de las cuatro veces que aparece este nombre en ac. en Paciano tres presente la forma iohannen, porque no existe razón alguna que abogue por la uniformidad. En su edición de los Annales de Tácito de la Bibliotheca Oxoniensis C. D. Fisher declina siempre el ac. Vologesen de Vologeses, mientras que C. Halm escribe una vez Vologaesem en la Bibliotheca Teubneriana ${ }^{70}$.

El pasaje de Paciano citado en segundo lugar es una frase de Simproniano, como lo demuestra el verbo adicis al que va subordinada. A esta subordinación se debe el ac. iohannen y, por tanto, no es posible atribuirlo sin más al hereje. El pasaje citado en quinto lugar es una frase literal de Simproniano, por lo que es lógico concluir que también éste usaba el ac. iohannen.

De todas estas consideraciones se concluye que el ac. iohannen del Reginensis es conforme con la enseñanza escolar de la época y con la tradición cristiana más antigua. En consecuencia, la lectura genuina es, con toda certeza, iohannen.

Isac

Certi denique sumus. ipso teste domino. et abraham et isac et iacob et omnes sanctos dei uiuere. (Bapt VI 6)

isac $R\left(\right.$ s.l. a $\left.R^{\prime}\right)$ isaac $R^{\prime} G P$ edd. omn. dei $R\left(\right.$ s.s. o $\left.R^{\prime}\right)$ deo $R^{\prime} G P$ edd. omn.

Tampoco isac es una forma excepcional. La antiquísima versión latina del Pentateuco escribe siempre isac ${ }^{71}$. La misma forma se lee en el Codex Bobiensis (K) de los Evangelios: deus isac y abraham genuit isac. isac genuit iaco ${ }^{72}$. En los mss de los Evangelios $a$ (Vercellensis s. v), $b$ (Veronensis s. v), $h$ (Claromontanus s. v) reza isac en Mt 8,$11 ; d$ (Codex Bezae Cantabrigiensis s. v), $f^{2}$ (Corbeiensis s. v), $h$ en Mt 22, 32; $f^{2} h$ escriben isach en Lc 3, 34 ${ }^{73}$. La versión latina de la Carta de Clemente de Roma a los Corintios traduce el nombre del Patriarca Isacus: Isacus cum confidentia, quod futurum erat, cognoscens ${ }^{74}$. Así pues, isac, con una sola $a$, está atestiguado en los S. II, III, IV y v. De ello se sigue con toda certeza que el escriba del Reginensis no comete ningún error al copiar isac en el texto de Paciano, antes bien es la lectura genuina y como tal debe ser restituida.

70 Vologaesen (Vologesen Fisher) Tac. Ann XII 14; 50; XIII 37; XIV 25; XV 5; 9; 13; 27; 31. Vologaesem Halm Ann. XIII 9, Vologesen Fisher.

71 U. Robert, Pentateuchi Versio Latina Antiquissima e codice Lugdunensi. Parisiis 1881 . Cf. n. 40 .

72 Hoogterp, Op. cit., p. 22.

${ }^{73}$ A. Jülicher, $O p$. cit., lugar correspondiente.

${ }^{74}$ Cap. 31. La pasión de los mártires Isac y Maximiano (s. Iv ?) escrita por el donatista Macrobio lleva el título: Passio Isacis et Maximiani (PL VIII 767). 


\section{Lucanum}

Habes additum secundum lucanum. (Tract. XV 4)

lucanum $R$ Brf lucam GP edd. omn.

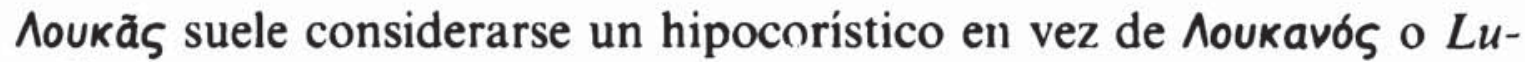
canus $^{75}$. Semejantes contracciones no son una rareza en el N. T. como

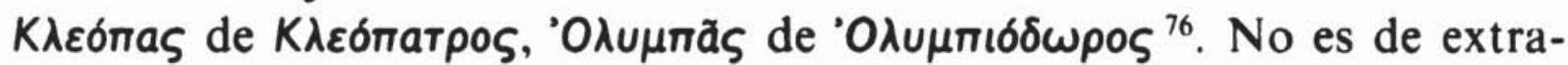
ñar, pues, que San Pablo en sus Cartas hable de su acompañante en un

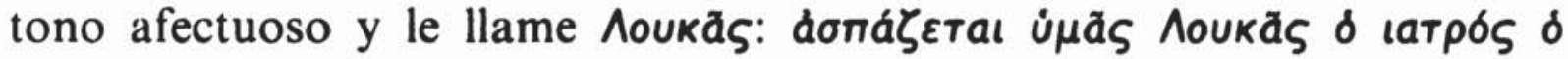

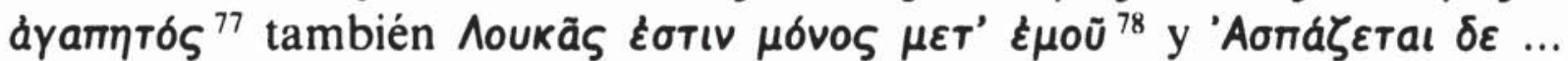
Noukã $\varsigma^{79}$. Th. Zahn ${ }^{80}$ alude a la posibilidad de que Lucas sea el nomen y Lucanus el cognomen. De hecho, los mss antiguos como $a, f^{2}$ rezan secundum lucanum, $e$ (Palatinus s. v) cata lucanum, $i$ (Vindobonensis s. v-vı) Iucani euangelium. El Fragmentum euangelii S. Lucae Ambrosianum (s. vi o anterior) contiene pasajes de c. 17, 18, 20, 21 del Evangelio con el epigrafe secundum lucanum ${ }^{81}$. Obsérvese que estos mss son contemporáneos o muy cercanos de Paciano.

Cipriano en sus tratados escribe in euangelio cata lucanum ${ }^{82}$ o simplemente cata lucanum ${ }^{83}$, nunca cata lucam o secundum lucam. Los primeros cristianos llamados Lucanus pertenecen a una época en que consta el epigrafe secundum lucanum o cata lucanum, es decir, el nombre $\mathrm{Lu}$ canus del Evangelista. Tertuliano refuta la enseñanza de un hereje Lucanus con estos términos: Viderit unus aliqui Lucanus ne huic quidem substantiae parcens, quam secundum Aristotelem dissoluens aliud quid pro ea subicit, tertium quiddam resurrecturus, qua Lucanus $^{84}$. Cipriano menciona dos veces a un acólito Lucanus: per ... Lucanum et Maximum et

75 M. J. Lagrange, Évangile selon saint Luc. París 1921, p. 5, manifiesta una cierta reserva. Dice: "Aoukăs passait pour être un abrégé du latin Lucanus".

${ }^{76}$ Lc. 24, 18; Rom, 15. Cf. Fr. Zorell, Lexicon Graecum Novi Testamenti, Parisiis 1904/1961, cols. 711,781 y 908 .

77 Col 4, 14.

78 II Tim 4, 11.

${ }^{74} \mathrm{Phm} 24$.

k0 Das Evangelium des Lucas, Leipzig 1913, p. 736.

* Ceriani, Fragmentum Evangelii S. Lucae Ambrosianum en Monumenta Sacra et profana I, fasc. 1, pp. 4-8, Mediolani 1861. Contiene fragmentos de los caps. 17, 18. 20, 21 del Evang. secundum Lucanum". Es del s. Iv o quizás algo posterior.

82 Quir II 11 (CCh SL III p. 44, 18); III 1 (Ib. p. 86, 113-114); 21 (Ib. p. 118. 128); 29 (Ib. p. 123, 13); 49 (Ib. p. 138, 2); 51 (Ib. p. 139, 3); 52 (Ib. p. 139, 8); 61 (Ib. p. 152, 11).

${ }^{* 3}$ Quir III 5 (CCh SL III, p. 93, 8); 11 (Ib. p. 100, 23); 13 (Ih. p. 105, 14); 16 (Ib. p. 109, 37); 19 (Ib. p. 11:3,9-10); 32 (Ib. p. 126, 9); 58 (Ib. p. 146, 41-42); II 7 (Ib. p. 39,25$) ; 19$ (Ib. p. 57,46$)$.

${ }_{84}$ Res. mort. II 12 (CCh SL II p. 924, 64-67). 
Amantium acoluthos ${ }^{85}$ y Lucanum et Maximum fratres nostros ${ }^{86}$. El Anónimo Aduersus haereses, cuya traducción latina debe ser del s. III o Iv, incluye a un Lucanus al que hace discipulo de Marción y que quizás sea el mismo hereje de Tertuliano: Extitit post hunc Lucanus quidam nomine, Marcionis sectator atque discipulus ${ }^{87}$. Este nombre de algunos cristianos se explica mejor por el prestigio del Evangelista Lucanus y, en consecuencia, es una confirmación de que tal fue el nombre de San Lucas $^{88}$.

Además de estos testimonios literarios, conviene recordar un sarcófago del s. v, conservado en el Museo de Arles, que representa a Jesucristo con los cuatro evangelistas, dos a cada lado y sosteniendo Marcos y Mateo un códice con su nombre y Lucas y Juan un volumen también con su nombre, dispuestos en este orden: MARCVS MATTEVS IESVS LVCANUS IOANNIS ${ }^{* 9}$.

Todas estas consideraciones nos conducen a la plena certeza de que la lectura secundum lucanum que figura en el Reginensis es la auténtica de Paciano y como tal debe ser restituida.

Pertenece al eminentísimo J. W. Ph. Borleffs el mérito de haber sido el primero en advertir la evidencia de esta lectura genuina, en 1939 , cuando arguyendo en contra de la atribución del De similitudine carnis peccati a Paciano por G. Morin, observó que «entre otras diferencias de lengua, es distinta la forma del nombre del Evangelista en ambos escritores, pues mientras el autor del tratado mencionado llama a Lucas por el nombre habitual, Paciano le llama Lucanus: secundum Lucanum, pues así hay que leer con $R$; además, también aparece así en otros escritores como, por ejemplo, Prisciliano" ${ }^{90}$.

${ }^{85}$ Ep. 77, 3, 1.

86 Ep. 79, 1.

${ }^{87}$ VI 3 (CCh SL II p. 1408, 8-10).

${ }_{88}$ A. Blaise, Dictionnaire Latin-Français des Auteurs Chrétiens, Turnhout 1954. p. $502 \mathrm{~b}$ escribe Lucanus titre ancien de l'évangile de $S^{\prime}$ Luc $(\mathrm{mms})$. Adviértase que anterior al testimonio de los mss está el de Cipriano y, aunque no anterior a todos los codd. más antiguos, también el de Paciano.

${ }^{89} \mathrm{G}$. B. de Rossi, Un sarcofago rivenuto in Roma posto a confronto con uno simile di Apt presso Avignone en Bulletino di Archeologia Cristiana 4, 1866, pp. 33-36; E. Le Blant, Étude sur les sarcophages chrétiens de la ville d'Arles 1878, p. 8; R. Garrucci, Storia dell'Arte Cristiana nei primi otto secoli della Chiesa. Collezione di tutti i monumenti di Pittura e Scultura incisi in rame su cinquecento tavole. Prato 1879, vol. V Sarcofagi ossia sculture cimiteriali Tav. 343, 3, p. 70.

90 Zwei neue Schriften Pacians? en Mn 7, 1939, p. 187. A. Gruber, observó que tambièn Prisciliano (Tract. 3, 60) usó la forma latinizada (Studien zu Pacian von Barcelona, p. 29). 
Moyses

Apud moseum (Paen III 2, 59)

Aput $R$. s.s. d $R^{f} \quad$ moseum $R$ fol $116^{\text {va }} L$ fol $42^{\text {th }} V$ Ang (exp. u eras. partim $\mathrm{m} R^{\prime}$ ) mosen $R^{\prime} G$ Gnd Migne moysen P Ag Flo Nog Pey Rub Mosem Til Gal Bigne.

Moyseum pro blasphematore populo deprecantem. sic appellat deus (Paen V I, $106 \mathrm{~s})$

moyseum $R$ fol $113^{\text {th }} L$ (s.l. s moiseum ex moieum $V$ fol $44^{\text {th }} V$ Ang (exp. u eras. partim $\mathrm{m} R^{\prime}$ ) moysen $R^{\prime} P$ edd. mosen $G$ Barth Gnd Migne mosem Til Gal Bigne blasphematore s.l. ma $e x$ blasphetore $V$ depraecantem $R$ oblitt. a deprecantem $R^{\prime}$ om. GP deus $R L V G$ edd. omn. dominus $P$.

ab adam usque ad moysen. Per moysen uero. unus tantum populus electus est. (Bapt I 3)

inquit moyses (Ep II, VIII 2)

et propter hoc deum. nec moyses nec paulus offendit (Ep II, VIII 2)

hoc deum. R fol $113^{\text {ra }}$ L GP Bigne ${ }^{4 x}$ Flo hoc deum fol $42^{\text {rh }}$ V Gial Ag Nog Pey Rub hoc, deum Til Bigne Gnd.

Nouatianus ... Iam cum Christo uidetur ut idem moyses (Ep II, VIII 3)

Quis hoc uindicat frater? Moyses. an paulus. an christus? at et moyses deleri e libro pro blasphematoribus optat (Tract. I 2)

et eras. $R$ om. GP edd. omn.

moyses deuteronomio testificante praedixit (Tract. XVII I)

Ianen uero et mambrem. sic restitisse moysi. sicut uos catholicis arbitramur. Inde sic ponit apostolus. Quia sicut iannes et mambres restiter moysi. (Tract. XXI 6; II Tim 3, 8)

Ianen $R\left(s . l\right.$. n $\left.R^{\prime}\right)$ iannen $R^{\prime} G P$ Iannen Pey' Iannem Gnd Rub Iamnem cett. edd. Iamnes $P$ edd. praeter Gnd Pey $R u b \quad$ restiter $R$ GP restiterunt edd. omn. locique a Sabatier adlati.

Nam quod cyprianum beatissimum. mihi pro contrario teste proponis. quia in epistula quae de lapsis. moysen et danihelum et iob orasse pro peccatoribus dicat nec impetrasse. dicente domino. etsi tres in medio eorum fuerint. noe iob et 
danihel. non liberabunt filios neque filias sed ipsi soli salui erunt. (Tract. XXII 3)

lapsis $R$ GP lapsis est edd. omn. moysen $R$ Til Bigne ${ }^{1} A g$ Gnd moysem GP Bigne Flo Noe (calc. Gnd) Pey Rub danihelum $R$ danihelem $G P$ edd. omn.

Gallandi en una nota a pie de página observa basándose en el pasaje del tratado De Lapsis de Cipriano a que alude Paciano: Moysen $\mid$ Aut Pacianus memoria lapsus, aut potius librarius aliud agens erravit. Rescribendum enim videtur 'Noe' pro 'Moysen', ad textum Ezechielis subiectum. Neque aliter sane S. Cyprianus 'de Lapsis' pág. 130 edit. Oxon. quo respicit $S$. Pater. Quae quidem emendatio ex iis confirmatur, quae habentur infra cap. $X X I V^{91}$. Repiten esta nota Migne y Peyrot. Éste es el primero en introducir en el texto la conjetura de Gallandi. Rubio la adopta también.

Veamos el texto del tratado De Lapsis:

Nam et Moses pro peccatis populi petit nec tamen peccantibus ueniam cum petisset accepit (sigue Ex. 32, 31-33). Ille amicus Dei, ille facie ad faciem locutus saepe cum Domino, quod petit impetrare non potuit, nec Dei indignantis offensam sua deprecatione placauit. Hieremiam Deus laudat et praedicat dicens (sigue Hier. 1,5) et eidem pro peccatis populi deprecanti frequentibus et oranti (sigue Hier. 11, 14 y 7, 16). Quid uero fortius Noe qui, cum repleta esset terra peccatis, solus inuentus est iustus in terris. Quid gloriosius Daniele, quid ad facienda martyria in fidei firmitate robustius, in Dei dignatione felicius, qui totiens et cum confligeret uicit et cum uinceret superuixit? Quid Iob in operibus promptius, in temptationibus fortius, in dolore patientius, in timore summissius, in fide uerius? Nec his tamen si rogarent, concessurum se Deus dixit. Cum propheta Ezechiel pro delicto populi deprecaretur (sigue Ez. 14, 16) ${ }^{42}$.

Paciano resume una afirmación de Simproniano relativa al De Lapsis, en cuyo tratado Cipriano atestigua que Moisés, Daniel y Job rezaron por los pecadores y no obtuvieron su perdón. Realmente, en el pasaje aludido Cipriano afirma que Moisés intercedió por los pecados del pueblo y, no obstante sus súplicas, no consiguió el perdón de los pecadores: Moses pro peccatis populi petit nec tamen peccantibus ueniam cum petisset accepit. Con esta frase concuerdan perfectamente las palabras de Paciano puestas en boca de Simproniano: in epistula quae de lapsis moysen et danihelum et iob orasse pro peccatoribus ... nec inpetrasse. La única conclusión que se puede sacar es que, según el testimonio de Pa-

91 Bibliotheca Veterum Patrum, Venetiis 1770, Tom. VII, p. 268, n. 4. Migne, $P L$ tom. XIII col. 1078 n. ; Peyrot, Paciani Barcilonensis Episcopi Opuscula, Zwollae 1896, p. $90(k)$.

92 Laps. 19 (CCh SL III p. 231 s, 372-394). 
ciano, Simproniano escogió a Moisés, Daniel y Job de entre los seis recordados por Cipriano, a saber, Moisés, Jeremías, Noé, Job, Ezequiel y, por la cita de este profeta, Daniel. Carece, por tanto, de todo fundamento alegar el texto de Ezequiel para sustituir Moysen por Noe. Debe restituirse la lectura Moysen del Reginensis como ciertamente genuina.

Ipsa tamen cypriani exempla te permouent. quibus et moysen et ceteros sanctos non impetrasse commemorat. (Tract. XXII 5)

Non uides moysen. pro quibus non impetrauerit. (Tract. XXIII 1) non ${ }^{2}$ om. GP.

Et tamen. quis tibi nostrum dixit. quod moyses non impetrauerit (Tract. XXIII 1)

et precatus est inquit moyses in conspectu domini sui (Tract. XXIII 2)

En estos trece pasajes recogidos la declinación del nombre de Moisés presenta tres casos, a saber, nominativo, acusativo y dativo ${ }^{93}$ con estas variedades: nom. Moyses, ac. moseum, moyseum, moysen, dat. moysi.

Las formas moyses, moysen, moysi son las más corrientes, incluso en la literatura pagana. Así en Tácito leemos: Moysen unum exulum ${ }^{94} ; \mathrm{Se}$ cutus Moyses coniectura herbidi soli largas aquarum uenas aperit ${ }^{95}$; Moyses ... nouos ritus contrariosque ceteris mortalibus indidit ${ }^{96}$. Juvenal escribe: ... ius | tradidit arcano quodcumque uolumine Moyses ${ }^{97}$. En cambio, el escoliasta de Juvenal dice legem Moyse ${ }^{98}$.

Cipriano ${ }^{99}$ declina nom. Moyses ac. Moysen gen. Moysi dat. Moysi. Prudencio ${ }^{100}$ nom. Moses, Moyses gen. Moysi dat. Moysi abl. Moysi. Tertuliano ${ }^{101}$ sigue una flexión más variada y en parte más cercana de

${ }_{93}$ Ilustra las diversas formas del nombre de Moyses el de Achilleus sobre el que puede verse M. Leumann, Der lateinische Genetiv Achilli en $M H$ 2, 1945, pp. 237 258.

${ }_{94}$ Hist. V 3, 2.

${ }^{95} \mathrm{Ib} . \mathrm{V} \mathrm{3}, 3$.

$96 \mathrm{~V} \mathrm{3}, 4$.

${ }^{97}$ Sat. XIV 102.

${ }_{98}$ Scholia ad S. VI 542. Cf. P. Wessner, Scholia in Iuuenalem uetustiora, Leipzig. Teubner, 1931/Stuttgart 1967, p. 108.

${ }_{94}$ Moyses Fort. 4 (CCh SL III p. 190, 2); 7 (Ib. p. 195, 15). Moysen Fort. 4 (CCh SL III p. 190, 6); 10 (Ib. p. 200, 35); Eccl. Unit. 18 (CCh $S L$ III p. 162, 440). Moysi Quir. III 32 (CCh SL III p. 127, 3); Eccl. Unit. 16 (Ib. p. 201, 406).

100 Moyses Hamart. 339 (CCh SL CXXVI p. 128); Per. 6, 86 (Ib. 317); Moysi (dat.) Apoth. 51 (CCh SL CXXVI p. 78); Moysi (abl.) Tit. Hist. IX 36; X 38 (CCh SL CXXVI p. 392). Moysi (abl.) Tit. Hist. 53 (CCh SL CXXVI p. 392).

101 Moses Idolol. V 3 (CCh SL II p. 1105, 3) et passim, Moyses Prax. XIV 8 (CCh SL II p. 1178, 59). Moysen Apol. XIX 3 (CCh SL I p. 121, 58) et passim. Moysis (gen.) Ie. X 9 (CCh SL II p. 1268, 33). Mosei (gen.) Bapt. IX 2 (CCh SL I 
Paciano: nom. Moses, Moyses ac. Moysen gen. mosei, Moysei, Moysi, Moysis dat. Moyseo, Moysi abl. Moyse.

Toda esta diversidad de formas se debe a la morfología que el nom-

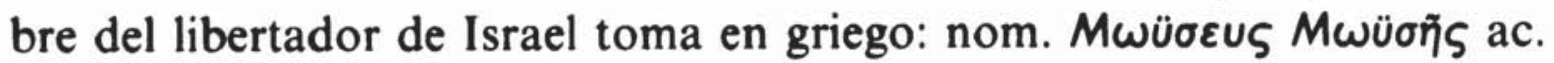

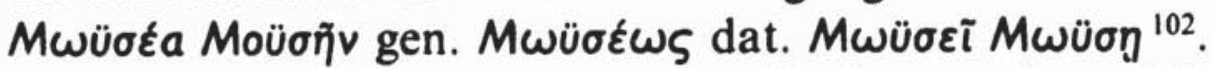

El nom. Moyses se explica por la forma griega del mismo caso. El ac. Moysen tiene su paralelismo en Plauto, quien hace en -en el ac. de nombres en -es, como Periphanen ${ }^{103}$ del ms Ambrosianus y de la recensión Palatina, Calliclen ${ }^{104}$ de la recensión Palatina, Stratophanen ${ }^{105}$ que en la misma recensión se lee strato pane nubilis es en vez de Stratophanen ubi is est ...? El ac. Moseum Moyseum sigue la declinación latina de los nombres griegos, normal en la prosa, conforme, no obstante, con el paradigma de Orfeo, nom. Orpheus ac. Orpheum ${ }^{106}$. Una excusa de Cicerón confirma el carácter latino de esta desinencia. Escribe a su amigo Atico: Venio ad 'Piraea', in quo magis reprehendendus sum quod homo Romanus 'Piraea' scripserim, non 'Piraeum' (sic enim nostri locuti sunt), quam quod addiderim 'in'. Non enim hoc ut oppido praeposui sed ut loco. Et tamen Dionysius noster et qui est nobiscum Nicias Cous non rebatur oppidum esse Piraea. Sed de re uidero. Nostrum quidem si est peccatum, in eo est quod non ut de oppido locutus sum sed ut de loco secutusque sum non dico Caecilium: Máne ut ex portu in Piraeum (malus enim auctor Latinitatis est), sed Terentium cuius fabellae propter elegantiam sermonis a C. Laelio scribi: Heri áliquot adulescéntuli coiimus in Piraeum, et idem,

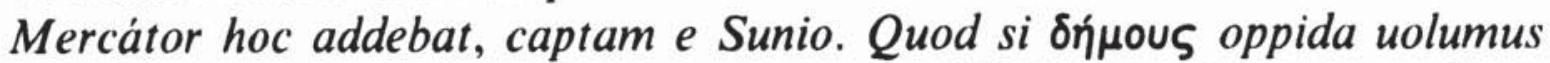
esse, tam est oppidum Sunium quam Piraeus ${ }^{107}$. El dat. Moysi no ofrece dificultad declinado por la tercera.

De todas estas consideraciones se desprende con toda certeza que la enmienda mosen y Moysen así como las formas de los mss $G P$ y las adoptadas por las ediciones son corruptas y la única lectura genuina es la del Reginensis: Moseum y Moyseum, y como tal debe ser restituida.

p. 284, 10); An. XXXV 6 (Ib. p. 838, 64); XXXVII (Ib. p. 839, 9); Res. mort. LV 8 (Ib. p. 1002, 32). Moysei (gen.) Hermog. XIX 1 (CCh SL I p. 412, 19); XXII 4 (Ih. p. 424, 27). Moysi (gen.) Iud. III 1 (CCh SL II p. 1344, 6); IX 21 (Ib. p. 1370, 147). Moysi (dat.) Apol. XIX 4 (CCh SL I p. 121, 63). Moyseo (dat.) Iud. IX 23 (CCh $S L$ II p. 1371, 164). Moyse (abl.) Carn. Chr. VI 4 (CCh SL II p. 884, 24).

102 Fr. Blass-A. Debrunner, Grammatik des neutestamentlichen Griechisch, Göttingen 1943 , I, p. 20,$38 ; 27,55,1$.

${ }_{103}$ Epid. 612.

104 Trin. 875.

105 Truc. 514. Véase también: M. Leumann, Der lateinische Genetiv Achilli en $M H 2,1945$, p. 239 s.

106 R. Kühner, Ausführliche Grammatik der lateinischen Sprache, Hannover 1877, I, pp. 225, 6; 299 Anmerk.; 318, 2.

107 Att. VII, III 10. 


\section{Neniuitas}

$$
\begin{aligned}
& \text { non neniuitas ... a praedicto interitu liberauit (Tract. XVI 5) } \\
& \text { neniuitas } R \text { (exp. e s.l. i } R^{\prime} \text { ) niniuitas } R^{\prime} G P \text { edd. omn. }
\end{aligned}
$$

A tenor de la forma más corriente niniuitas, y dada la confusión de $e$ por $i$ y viceversa en $R$ en el texto de Paciano, la corrección floriana no deja de ser muy tentadora: niniuitas. Sin embargo, el himno de Prudencio que canta a los que practican el ayuno dice: In Nineuitas se coactus percito | gressu reflectit ${ }^{108}$.

Si Prudencio escribió nineuitas bien pudo escribir Paciano neniuitas. Nada obsta, pues, a la restitución de esta lectura como auténtica.

\section{Solomonis}

Solomonis quoque sententiam non tacere (Tract. XX 3)

solomonis $R$ Salomonis fol $114^{\text {va }} \mathrm{L} \quad$ fol $43^{\text {ra }} \mathrm{V}$ GP edd. omn.

En el texto de Paciano el Reginensis presenta cinco veces la corrupción de $o$ en vez de $a$ : destinato por destinata ${ }^{109}$, quotidiano por quotidia$n a^{110}$, infamore por infamare ${ }^{111}$, dextero por dextera ${ }^{112}$, nouationi por nouatiani ${ }^{113}$. No es ésta una confusión insólita. S. Hedberg cita a primo por optimo pasando por aptimo en los mss de Columella pertenecientes al s. $\mathrm{xv}^{114}$. J. M. Hunt ${ }^{115}$ enumera quince casos de la confusión inversa del tipo: pateris por poteris en Horacio. A primera vista no parecería fuera de lugar la sospecha de que solomonis del Reginensis debiera sumarse a las cinco corrupciones mencionadas $\mathrm{y}$, por tanto, hubiese de preferirse Salomonis de los otros mss y de las ediciones. Prestemos ahora nuestra atención a algunos testimonios escriturísticos y literarios.

El título del Libro de la Sabiduría reza $\sum o \phi i ́ a ~ \sum a \lambda \omega \mu \tilde{\omega} v o \varsigma^{116}$. En

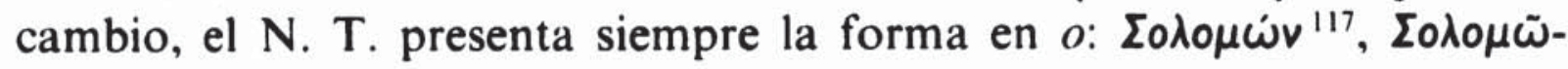

${ }^{108}$ Cathem. VII 131 (CCh SL CXXVI p. 39).

109 Paen II 2, 36. fol 39" lin. $22 R$.

110 Paen X 6, 279 fol $43^{r}$ lin. $23 R$.

III Tract. V 4 fol $66^{*}$ lin. $18 R$.

112 Tract. V 5 fol $66^{\circ}$ lin. $25 R$.

113 Tract. XVIII 5 fol. $72^{v}$ lin. $12 R$.

114 Contamination and Interpolation. A Study of the 15th Century Columella mss, Upsala 1968, p. 52.

${ }_{115}$ Cinq explications de textes en Ant. Clas. 43, 1974, p. 356. Hor. Epist. I, 16, 30.

116 A. Rahlfs, Septuaginta. Id est Vetus Testamentum graece iuxta LXX interpretes $^{8}$, Stuttgart 1935/1965, II, p. 345.

${ }^{117}$ Mt 1, 7; 6, 29; Act 7, 47. 


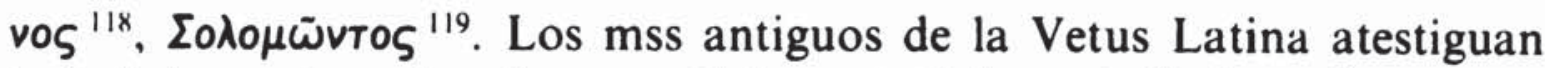
indistintamente ambas formas: Salomonis Solomonis ${ }^{120}$. Lo mismo conviene decir de los mss latinos más antiguos de los Evangelios en los pasajes citados ${ }^{121}$.

Cipriano en sus tratados emplea 42 veces la forma en $o$ : Solomonem, Solomonis, Solomoni, Solomone ${ }^{122}$, mientras que la forma en $a$ aparece sólo 7 veces: Salomonem, Salomoni, Salomone ${ }^{123}$. En Tertuliano leemos 10 veces la forma en $o$ : Solomon, Solomonem, Solomonis, Solomoni, Solomone ${ }^{124}$, mientras que la forma en $a$ es un poco más frecuente, 12 veces: Salomon, Salomonem, Salomonis, Salomoni, Salomone ${ }^{125}$. Lactancio

${ }^{118}$ Mt 12, 42; Lc 11, 31; Ioh 10, 23.

119 Act 3, 11; 5, 12. Véase también Fr. Blass-A. Debrunner, Op. c. p. 27, 55, 2.

${ }_{120}$ W. Thiele, Sapientia Salomonis. Vetus Latina. Die Reste der Altlateinischen Bibel nach Petrus Sabatier neu gesammelt und herausgegeben von der Erzabtei Beuron, Freiburg i./Br. 1977, p. 241 s.

121 A. Jülicher, Itala. Das Neue Testament in altlateinischer Uberlieferung nach den Handschriften herausgegeben von --.Matthaeus' Evangelium y Verzeichnis der Handschriften, p. VII.

122 Solomonem: Quir. I 3 (CCh SL III p. 8, 24); 20 (Ib. p. 21, 3); II 1 (Ib. p. 28. 3); 2 (Ib. p. 30, 4); III 1 (Ib. p. 82, 44); 6 (Ib. p. 94, 3); 8 (Ib. p. 96, 2); 11 (Ib. p. $99,8) ; 12$ (Ib. p. 103, 2); 30 (Ib. p. 124, 2); 35 (Ib. p. 129, 3); 50 (Ib. p. 138, 2); 51 (Ib. p. 138, 2); 53 (Ib. p. 140, 6); 61 (Ib. p. 151, 16); 66 (Ib. p. 156, 5); 80 (Ib. p. 163 . 8); 86 (Ib. p. 164, 3); 93 (Ib. p. 168, 2); 96 (Ib. p. 168, 2); 97 (Ib. p. 169, 2); 102 (Ib. p. 172, 3); 107 (Ib. p. 173, 10); 108 (Ib. p. 174, 8); 109 (Ib. p. 174, 2); Fort. 9 (Ib. p. 198,5$) ; 11$ (Ib. p. 205,95$) ; 12$ (Ib. p. 211, 3).

Solomonis: Quir. II 14 (CCh SL III p. 47, 2); III 6 (Ib. p. 96, 31); 15 (Ib. p. 106. 8); 16 (Ib. p. 107, 2); 20 (Ib. p. 114, 4); 56 (Ib. p. 142, 2); 58 (Ib. p. 144, 21); 59 (Ib. p. 146, 2); Fort. 1 (Ib. p. 187, 7); Eccl. Unit. 7 (Ib. p. 254, 180).

Solomoni: Quir. III 80 (CCh SL III p. 162, 5).

Solomone: Quir. III 62 (CCh SL III p. 154, 18); Eccl. Unit. 7 (Ib. p. 254, 176); 20 (Ib. p. 264,486$)$.

123 Salomonem: Mort. 23 (CCh SL III A p. 29, 388); Op. eleem. 5 (Ib. p. 57, 84);

9 (Ib. p. 60, 179); Fort. 1 (Ib. III p. 188, 16).

Salomoni: Dom. Or. 25 (CCh SL III A p. 106, 484).

Salomone: Dom. Or. 25 (CCh SL III A p. 106, 482); Hab. uirg. 1.

124 Solomon: Iud. VII 7 (CCh SL II p. 1355, 48); Marc. V, IX 11 (Ib. I p. 691,

19): Praescr. haer. III 4 (Ib. p. 188, 10).

Solomonem: Marc. V, IX 12 (CCh SL I p. 691, 12).

Solomonis: Nat. II 2 (CCh SL I p. 42, 7); Praescr. haer. VII 10 (Ib. p. 193, 34);

Scorp. VII 1 (Ib. II p. 1081, 28); Val. II 2 (Ib. p. 754, 23).

Solomoni: Marc. V, IX 10 (CCh SL I p. 691, 10).

Solomone: Marc. V, IX 12 (CCh SL I p. 691, 25).

125 Salomon: Marc. II 23. I (CCh SL I p. 500, 14); III 20 (Ib. p. 536, 10); IV 29. 1 (Ib. p. 624, 27); Pud. 18, 3 (Ib. II p. 1317, 8).

Salomonem: Iud. XIV 12 (CCh SL. II p. 1395, 96); Marc. III 20, 8 (Ib. I p. 536,

4 y 5); IV 11,8 (Ib. p. 567,8$) ; 15,8$ (Ib. p. 579, 15).

Salomonis: Monog. VI 4 (CCh SL I p. 123, 41). 13).

Salomoni: Iud. XIV 13 (CCh SL II p. 1395, 101); Marc. III 20, 9 (Ib. I p. 536,

Salomone: Carn. XVIII 1 (CCh SL II p. 905, 4). 
of rece 10 veces la forma en $o$ : Solomon, Solomonem, Solomonis, Solomo$n e^{126}$, Solomonium templum ${ }^{127}$. En cambio, la forma en $a$ se lee una sola vez: Salomon ${ }^{128}$.

A tenor de estas consideraciones no cabe argumento alguno definitivo contra la autenticidad de Solomonis en Paciano.

\section{Conclusión}

El objeto de estas páginas ha sido restituir la forma genuina de algunos nombres hebreos en Paciano modificados por la mayoría de mss y por las ediciones. El lector se preguntará quizás también por la línea o tradición a que pertenece Paciano. La respuesta supondría una larga investigación que excedería los limites de un artículo y necesitaría los datos de unas monografias de las que no se dispone todavía ${ }^{129}$. Con las confrontaciones realizadas en el presente estudio se ha compuesto un cuadro que permite resumir de algún modo los paralelismos principales.

Paciano concuerda con Tertuliano y Prudencio en beliae, discrepa de todos en beliab. Concuerda con Cipriano y Ambrosio y, en parte, con Jerónimo en belzebul, frente a belzebulem, -is de Tertuliano y Prudencio. Con Tertuliano y Cipriano presenta daniel, con sólo Cipriano danihel. En Danielus hay paralelismo con Prudencio y, en parte, con Tertuliano que declina ac. Danielum. En danihelo coincide con Tertuliano y, en parte, con Cipriano por cuanto hace el ac. Danihelum. Discrepa, en cambio, de ambos cuando declinan por la tercera. En ezechielum sigue paralelo con Cipriano frente a Tertuliano que declina por la tercera. En lucanum concuerda sólo con Cipriano. En moseum y moyseum ac. coincide sólo muy parcialmente con Tertuliano que declina gen. Moysei, Mosei dat. Moyseo. Diriase más bien que Paciano se halla en la tradición de Cipriano y cuando se aparta de éste concuerda, salvo alguna rara excepción, con Tertuliano. Semejante correspondencia era de

126 Solomon: Diu. Inst. IV 12 ( (SEL. XIX I p. 310. 4); 13 (Ih. p. 323. 9 y 12): 16 (Ib. p. 339,1 ); 18 (Ih. p. 359,9 ).

Solomonem: Diu. Inst. IV 6 (CSEL XIX I p. 290, 3): 8 (Ih. p. 297, 19); Epit. 39 (Ib. p. 715, 17).

Solomonis: Diu. Inst. IV 13 (Ih. p. 324, 3).

Solomone: Diu. Inst. IV 16 (CSEL XIX 1 p. 340. 7).

127 Diu. Inst. IV 13 (CSEL XIX 1 p. 324, 9).

128 Epit. 40 (CSEL XIX 1 p. 717, 6).

129 Puede consultarse, no obstante, Fr. Wutz, Onomastica Sacra. Untersuchungen zum Liber Interpretationis Nominum Hehraicorum des hl. Hieronymus. Leipzig 1914 pp. XVII-XXVII; G. Rudberg. Neutestamentlicher Text und nomina sacra. Skrifter utgifna af $k$. Humanistika Vetenskaps-Samfundet $i$ Uppsala 17/3. Upsala - Leipzig 1915; C. H. Turner, Formulare of Quotation for Old Testament en JThSt VI (1915/ 1965) pp. 248-270. 
esperar si se tiene en cuenta que Cipriano y Tertuliano son las fuentes más importantes de Paciano. Para una mayor precisión en la línea ascendente sólo se puede decir que Cipriano pertenece a un grupo muy distinto del de Origenes ${ }^{130}$.

Se observa que Floro de Lyón corrige belzebul en behelzebub, principem en principe, isac en isaac, moseum en mosem, moyseum en moysen, enmiendas arbitrarias que han pasado al $\mathrm{ms} G$ y de éste al $P$. La arbitrariedad de semejantes modificaciones y el hecho de encontrarse en $G$ y $P$ confirma lo que yo había demostrado en 1967 , es decir, que $R$ es el modelo de $G$ y éste de $P^{131}$.

Ángel Anglada

\section{Sinopsis de LA DECLINACIÓN DE LoS NOMBRES ESTUdiados}

\section{Belia}

ac. beliab Pac.

dat. beliae Pac. Tert. $\beta \varepsilon \lambda i n$ Gregorio Nacianceno

nom. belia Prud.

beliar Hier.

belial Hier.

dat. belial Tert.

abl. belia Prud.

belzc'bul

ac. belzebul Pac. Cypr. codd. Euangel. $k$ s. Iv-v, $d$. s. v. e s. v. belzebulem Tert.

nom. belzebul Hier

belzebub como más correcto Hier.

gen. belzebulis Prud.

abl. bezebul Ambr.

belzebule Tert.

danihelus

nom. danihelus Pac.

danielus Prud. Ammianus Marc. Pac.

danihel Pac. Cypr. Lucifer Calar.

daniel Pac. Tert. Cypr.

ac. danihelum Pac. Iren. (uersio lat.), Tert.

danielum Ammianus Marc.

danielem Tert. Lucifer Calar.

${ }^{130}$ Fr. Wutz, Op. c. p. 11.

131 Ángel Anglada, La tradición manuscrita de Paciano de Barcelona en emerita 35, 1967, pp. 138-161. 
dat. danihelo Pac. Tert. Lucifer Calar.

danielo Iren. (uersio lat.)

daniheli Tert. Cypr.

danieli Tert.

gen. danielis Tert. Lucifer Calar. $\Delta a v i n j \lambda o u$ ms D s. v-vı

abl. danihelo Tert.

danihele Cypr.

daniele Tert.

Ezechielum

ac. ezeclielum Pac.

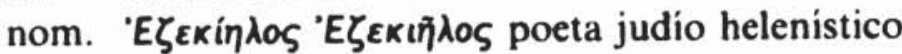

Iohannes

nom. iohannes Pac. iohannis Pac.

ac. iohannen Pac. codd. Euangel. $a$ s. Iv, $b$ s. v, $f$ s. vi iohannē Pac. $\operatorname{cod} f$ s. vi

gen. iohannis Pac.

Isac

nom. isac Pac. Pentateuchi uersio latina antiquissima, codd. Euangel. $a$ s. Iv, $b$ s. v, $h$ s. v, k s. Iv-v. isacus: Clemens Rom. (uersio latina).

\section{Lucanum}

ac. lucanum Pac. codd. Euangel. $a f^{2} \mathrm{e}$

gen. lucani cod. Euangel. i

nom. lucanus en nombres de cristianos s. III.

Moyses

nom. Moyses Pac. Tert. Cypr. Prud. Tac. Iuu.

ac. moseum Pac.

moyseum Pac.

moysen Pac. Tert. Cypr. Tac.

dat. moysi Pac. Tert. Cypr. Prud.

nom. moses Tert. Prud.

gen. moysi Tert. Cypr. Prud.

moysei Tert. schol. in Iuu.

mosei Tert.

moysis Tert.

dat. moyseo Tert.

muysi Tert. Cypr. Prud.

abl. moysi Prud.

moyse Tert.

\section{Solomonis}

gen. solomonis Pac. Tert. Cypr. Lact.

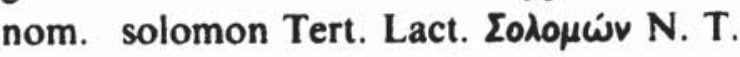

ac. solomonem Tert. Cypr. Lact. 


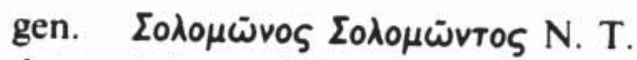

dat. Solomoni Tert. Cypr.

abl. Solomone Tert. Cypr. Lact.

nom. salomon Tert. Lact.

ac. Salomonem Tert. Cypr.

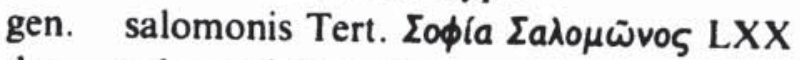

dat. salomoni Tert. Cypr.

abl. salomone Tert. Cypr. 